REVIEW

\title{
Heart and mind: (2) psychotropic and cardiovascular therapeutics
}

\author{
S U Shah, Z Iqbal, A White, S White
}

Postgrad Med J 2005;81:33-40. doi: 10.1136/pgmi.2003.015230

There is a plausible biological basis for the association between psychiatric morbidity and cardiovascular disease. Anxiety, panic disorder, and depression are common in patients with coronary heart disease and hypertension. Despite this evidence there is poor recognition of anxiety disorders and depression in primary care and hospital medical practice. Concern also surrounds the use of psychotropic drugs in patients with cardiovascular disease. In the first of the two articles on this subject, we highlighted the current evidence regarding the association between cardiovascular and psychotropic conditions. In this second article, we discuss the interaction of the drugs used in the management of these two varied but commonly coexistent group of diseases as well as their relative effects on either system. Finally, we summarise the data regarding the safe use of these medications based on the recommendations from the currently available evidence.

See end of article for authors' affiliations

Correspondence to:

Correspondence to:
Dr Saeed Ullah Shah, Department of Cardiology, Ysbyty Gwynedd, Bangor, North Wales, UK; saeedshah@miranshah. freeserve.co.uk

Submitted

19 September 2003

Accepted 7 August 2004
I the companion paper to this article, we highlighted the association between neuropsychiatric illnesses and cardiovascular diseases. ${ }^{1}$ Both conditions, in particular depression and ischaemic heart disease, are common in the general population. Indeed, the Global Burden of Disease Study found that depression is second only to ischaemic heart disease as a cause of disability and early death in industrialised countries. ${ }^{2}$ Although rates of depression are high in the general community, they are even higher in patients with cardiac illnesses. Other psychiatric conditions such as anxiety disorders and psychotic illnesses such as schizophrenia are also not uncommon. Given the wide prevalence of both sets of disease, it is quite likely that in a considerable number of patients these illnesses will coexist. Drugs used to treat depressive and psychotic conditions in particular have been shown to have significant cardiac effects and important pharmacological interactions with medications used to treat cardiovascular diseases. Conversely, some cardiac drugs have also been implied in causing psychiatric symptoms. It is therefore important to understand the actions, side effects, and interactions of the drugs used in treatment of these two varied groups of diseases.

A comprehensive discussion of these effects and interactions is beyond the scope of this review, which is mainly addressed to cardiologists and other medical physicians. Readers should refer to other texts for a more in-depth review. In the following sections we will briefly discuss the pharmocological profiles, cardiac actions, and side effects of the major classes of psychotropic drugs. In addition, we will also review the neuropsychiatric effects of commonly used cardiovascular drugs. In the final sections, we will highlight and summarise the recommendations for use of psychotropic medications in specific cardiovascular disorders.

\section{EPIDEMIOLOGY}

Although there are no exclusive data on the extent of cardiac effects and interaction of psychotropic medication with drugs used in treating cardiovascular conditions, some inference can be derived from the epidemiological, observational, and anecdotal evidence available from various sources. Medications range from the anxiolytics that, in general, are relatively safe with minimal cardiac effects, to antidepressants (tricyclic and monoamine oxidase inhibitors antidepressants in particular) and antipsychotics that have been shown to have multiple cardiac effects including increased incidence of cardiac arrhythmias and possibly sudden cardiac death.

Because many cardiac and psychotropic agents lower blood pressure, additive hypotensive effects are not uncommon, as for example between the tricyclic antidepressants and antihypertensives. Many psychotropic agents slow conduction and prolong the PR, QRS, and QT intervals, and synergistic effects can occur when they are used in conjunction with antiarrhythmic medications, resulting in heart block or the long QT syndrome. Selective serotonin reuptake inhibitors (SSRIs; for example, fluoxetine, sertraline, paroxetine, and fluvoxamine) are bound to plasma proteins and can displace other proteinbound drugs, thereby increasing the level of active drug and resulting in possible toxicity.

Antipsychotic (neuroleptic) drugs have generally been regarded as a group of drugs with a good margin of safety, but there have been regular case reports of sudden death associated with these agents since the 1960s. ${ }^{3-6}$ The part played by antipsychotic drugs is often uncertain, but when sudden death occurs in previously healthy young individuals a common conjecture is that medication was responsible. This concern follows several reports of unexpected deaths in young people, usually males, where the concurrent prescription of antipsychotic drugs has

Abbreviations: CSM, Committee on Safety of Medicines; GABA, gamma amino butyric acid; SSRI, selective serotonin reuptake inhibitor 
been implicated..$^{78}$ There are insufficient data to prove that sudden death is more likely among people being treated with antipsychotic medication than it is among the general population. However, there are no data that prove that there is no causal relationship between the use of this group of drugs and sudden death. Further, the Committee on Safety of Medicines (CSM) has received reports of 31 cases of unexplained sudden death and 63 reports of fatal cardiac arrest/arrhythmias in association with people treated with various antipsychotic drugs, covering the period that each drug was introduced up to May 1996.

Abnormalities seen on electrocardiography are relatively common in people receiving neuroleptics, occurring in around $25 \%$ of patients receiving this class of medications. ${ }^{10}{ }^{11}$ There are numerous reports of ventricular arrhythmias associated with repolarisation disturbances such as prolonged QT intervals, widening of QRS complexes, depression of ST segments, and most commonly abnormal $\mathrm{T}$ morphology or large U waves. ${ }^{1-19}$ They are observed more often in patients with pre-existing heart disease. ${ }^{20}$ In another study, QTc (QT interval corrected for heart rate) prolongation (>420 ms) was found to be significantly more common $(23 \%)$ in a sample of 111 chronic inpatients with schizophrenia receiving antipsychotic medication than in 42 age matched, drug-free controls $(2 \%){ }^{21}$ Thioridazine and, less frequently, chlorpromazine have been particularly implicated in the development of ventricular tachycardia, primarily in patients taking overdoses. ${ }^{22}$ Thioridazine in particular was found to be significantly more likely to cause tachycardia, a prolonged QT interval, prolonged QTc (>450 ms), a widened QRS (>100 ms), and arrhythmias. $^{23} 24$ Electrocardiographic abnormalities have also been found in $10 \%$ of patients treated with pimozide. ${ }^{25}$ Indeed, from 1971 to 1995, the CSM received 40 reports (16 fatal) of serious cardiac reactions, predominantly arrhythmias, with pimozide. ${ }^{26}$ It has also been suggested that antipsychotic drugs may be responsible for a toxic cardiomyopathy, leading to death by ventricular fibrillation or cardiac arrest. Ultrastructural damage to the heart associated with circulating autoantibodies, especially those to skeletal muscle, heart, DNA, mitochondria and smooth muscle, has been found in patients who have died from drug related, fatal arrhythmias. ${ }^{27}$ Further, clozapine has been associated with myocarditis, which has been found in cases of sudden death. ${ }^{28-30}$

Data regarding tricyclic antidepressants and the mortality associated with its cardiac effects are also not straightforward. Cardiac effects are generally associated with ingestion of bigger doses and in vulnerable patients. Although not all deaths or hospital admissions associated with the use of antidepressants are due to their cardiac effects, however, it will contribute to the majority of these incidents. Overall, the average death rate associated with single-ingested antidepressant toxicity is 0.00034 per year of treatment. In other words, one fatality may be expected for about every 3000 patients treated for one year. However, tricyclic antidepressants (excluding lofepramine) have a substantial cardiovascular toxicity and a higher associated fatality rate, 0.00058 per year of treatment, approximately one fatality for every 1750 patients treated for one year. SSRIs as a group are relatively safe, with a group fatality rate of 0.000010 per year of treatment, approximately one fatality for every 100000 patients treated for one year. One second generation tricyclic antidepressant appears atypical: lofepramine features a fatality rate similar to the SSRIs of 0.000017 per year of treatment, approximately one fatality for every 59000 patients treated for one year, and statistically this is not significantly different from the SSRIs as a group. ${ }^{31}$ It is only possible to make reasonable estimates of toxicity where substantial use is made of specific drugs. One or more of the lesser used tricyclic or related antidepressants may have relatively safe toxicity, but this is uncertain.

\section{USE OF PSYCHOTROPIC DRUGS IN CARDIOVASCULAR CONDITIONS (TABLE 1) Anxiolytics/hypnotics}

Of the anxiolytics and hypnotic agents used to treat anxiety and sleep disorders, benzodiazepines and the newer hypnotics are now the most widely used group. Approximately 20 benzodiazepines derivatives are currently available. They bind to specific, high affinity sites on the cell membrane parallel to the receptors for gamma amino butyric acid (GABA). The binding of benzodiazepines increases the affinity of GABA receptors for this neurotransmitter causing hyperpolarisation and inhibition of neural firing. Benzodiazepines are used in treating the anxiety that accompanies some form of depression and schizophrenia. They are very useful in treating panic disorders and are also used as sedatives, anticonvulsants, and muscle relaxants.

Anxiety disorders, especially panic and generalised anxiety disorder and disturbed sleep pattern, are prevalent in patients with cardiac disease. Hospitalised cardiac patients are acutely anxious, and because anxiety itself can threaten cardiac status, benzodiazepines have been widely used in coronary care units. They are considered as one of the safest groups of drugs in cardiovascular diseases. They are generally shown to be free of cardiac side effects and can be used safely in seriously ill cardiac patients, even in the period immediately after myocardial infarction. ${ }^{32}$ They can, however, decrease respiratory drive in patients with chronic obstructive pulmonary disease and chronic hypercapnia. No significant work has been done to assess the effects of using benzodiazepines on cardiac mortality or morbidity. In one small study, however, diazepam was shown to reduce myocardial contractility and increase myocardial blood flow by probably causing coronary vasodilatation when given intravenously. ${ }^{33}$ Overall, given the paucity of work done in this field, it would be prudent to restrict the use of anxiolytics for a short period of time if indicated in an acute cardiac event.

Larger doses of hypnotic agents can cause respiratory insufficiency and could thus indirectly affect vulnerable cardiovascular patients. Barbiturates are more toxic and should be completely avoided in cardiac conditions. Chloral hydrate is contraindicated in severe heart disease, particularly in heart failure, where it has been shown to react with frusemide. ${ }^{34}$

\section{Antidepressants (tables 2 and 4 )}

Major depression is an insidious mood altering condition affecting sleep, appetite, libido, and the ability to function. Cross sectional and case-control studies have shown that rates of depression are higher among patients with coronary artery disease. Follow up of patients after myocardial infarction has shown that they have a worse prognosis than nondepressed patients. Antidepressants are generally used effectively in treating a whole range of depressive disorders. The main classes of antidepressants include tricyclic/polycyclic agents, SSRIs, serotonin and noradrenaline (norepinephrine) reuptake inhibitors, and monoamine oxidase inhibitors.

Tricyclic antidepressants inhibit the neuronal reuptake of noradrenaline and serotonin into presynaptic nerve terminals. By blocking the major route of neurotransmitter removal, they lead to increased concentrations of monoamines in the synaptic cleft, resulting in antidepressant effects. They also block serotonergic, $\alpha$-adrenergic, histamine, and muscarinic receptors. The important drugs in this group are imipramine, amitriptyline, desipramine, nortriptyline, protriptyline, and doxepin. SSRIs are chemically unique antidepressants. They specifically inhibit serotonin reuptake. 


\begin{tabular}{|c|c|c|c|}
\hline & Lower risk & Moderate risk & High risk \\
\hline Antipsychotics & $\begin{array}{l}\text { Amisulpride } \\
\text { Butyrophenones } \\
\text { Flupenthixol } \\
\text { Quetiapine } \\
\text { Sulpiride }\end{array}$ & $\begin{array}{l}\text { Clozapine } \\
\text { Loxapine } \\
\text { Phenothiazines } \\
\text { Risperidone } \\
\text { Zotepine } \\
\text { Olazepine }\end{array}$ & $\begin{array}{l}\text { Pimozide } \\
\text { Thioridazine }\end{array}$ \\
\hline Antidepressants & $\begin{array}{l}\text { Mianserin } \\
\text { Mirtazapine } \\
\text { SSRls } \\
\text { Trazodone } \\
\text { Tryptophan } \\
\text { Viloxazine }\end{array}$ & $\begin{array}{l}\text { Moclobemide } \\
\text { Nefazodone } \\
\text { Reboxetine } \\
\text { Tricyclics } \\
\text { Venlafaxine }\end{array}$ & \\
\hline Anticonvulsants & $\begin{array}{l}\text { Benzodiazepines } \\
\text { Gabapentin } \\
\text { Lamotrigine } \\
\text { Valproate } \\
\text { Vigabatrin }\end{array}$ & $\begin{array}{l}\text { Carbamazepine } \\
\text { Phenytoin } \\
\text { Tiaqabine } \\
\text { Topiramate }\end{array}$ & \\
\hline Anxiolytics + hypnotics & $\begin{array}{l}\text { Benzodiazepines } \\
\text { Buspirone } \\
\text { Zopiclone }\end{array}$ & $\begin{array}{l}\text { Beta blockers } \\
\text { Chloral } \\
\text { Clomethiazole } \\
\text { Zolpidem }\end{array}$ & \\
\hline Others & $\begin{array}{l}\text { Acamprosate } \\
\text { Lithium }\end{array}$ & $\begin{array}{l}\text { Anticholinergics } \\
\text { Dexamfetamine } \\
\text { Donepezil } \\
\text { Modafinil } \\
\text { Paraldehyde } \\
\text { Rivastigmine }\end{array}$ & Disulfiram \\
\hline
\end{tabular}

They, therefore, have fewer anticholinergic and thus cardiac side effects. Serotonin and noradrenaline reuptake inhibitors are the newest antidepressant agents. They block the neuronal reuptake of serotonin and noradrenaline. Monoamine oxidase inhibitors are the least used antidepressants. They irreversibly or reversibly inactivate this enzyme, leading to accumulation and increased concentrations of this neuro- transmitter in the synaptic space. This causes activation of noradrenergic and serotonin receptors and may be responsible for the antidepressant action of these drugs.

Tricyclic antidepressants have multiple cardiovascular side effects. They increase catecholamine activity resulting in cardiovascular stimulation. ${ }^{35}$ The tricyclic antidepressants have type Ia antiarrhythmic properties (quinidine-like

Table 2 Commonly used antidepressants, dosages, general and cardiovascular side effects

\begin{tabular}{|c|c|c|c|c|}
\hline Agent & Starting dose & Maximum dose & General side effects & Cardiovascular effects \\
\hline \multicolumn{5}{|c|}{ Serotonin reuptake inhibitors } \\
\hline Sertraline & $12.5-25 \mathrm{mg} /$ day & $200 \mathrm{mg} /$ day & $\begin{array}{l}\text { Sexual dysfunction, nausea, } \\
\text { diarrhoea, headache }\end{array}$ & Benign bradycardia \\
\hline Fluoxetine & $5-10 \mathrm{mg} /$ day & $80 \mathrm{mg} /$ day & $\begin{array}{l}\text { Anxiety, agitation, insomnia, } \\
\text { somnolence, sedation }\end{array}$ & \\
\hline Paroxetine & $10 \mathrm{mg} /$ day & $50 \mathrm{mg} /$ day & Tremor & \\
\hline \multicolumn{5}{|l|}{ Tricyclics } \\
\hline Amitriptyline & $10-25 \mathrm{mg}$ at bedtime & $300 \mathrm{mg} /$ day & $\begin{array}{l}\text { Sedation, somnolence, dry mouth, } \\
\text { blurry vision }\end{array}$ & $\begin{array}{l}\text { Increase QT, PR, QRS intervals, } \\
\text { decreased T wave amplitude }\end{array}$ \\
\hline Imipramine & $10-25 \mathrm{mg}$ at bedtime & $300 \mathrm{mg} /$ day & Constipation, urinary retention & Tachycardia, arrhythmias \\
\hline Nortriptyline & $10 \mathrm{mg} /$ day & $150 \mathrm{mg} /$ day & Anxiety, insomnia, weight gain & Postural hypotension \\
\hline Desipramine & $25 \mathrm{mg} /$ day & $300 \mathrm{mg} /$ day & & \\
\hline \multicolumn{5}{|l|}{ Psychostimulants } \\
\hline Methylphenidate & $2.5 \mathrm{mg}$ twice a day & 20 mg twice a day & $\begin{array}{l}\text { Anxiety, agitation, insomnia } \\
\text { Anorexia, paranoia }\end{array}$ & Tachycardia (mild), hypertension (mild) \\
\hline \multicolumn{5}{|l|}{ Other agents } \\
\hline Bupropion & $75 \mathrm{mg} /$ day & $\begin{array}{l}150 \mathrm{mg} \text { three times } \\
\text { a day }\end{array}$ & $\begin{array}{l}\text { Anorexia, nausea, anziety, } \\
\text { agitation, insomnia, seizures }\end{array}$ & \\
\hline Venlafaxine & $12.5 \mathrm{mg}$ twice a day & $\begin{array}{l}125 \mathrm{mg} \text { three times } \\
\text { a day }\end{array}$ & $\begin{array}{l}\text { Headache, sexual dysfunction, } \\
\text { anxiety, insomnia, somnolence, } \\
\text { dizziness }\end{array}$ & Hypertension (dose related) \\
\hline Trazadone & $25 \mathrm{mg} /$ day & $600 \mathrm{mg} /$ day & $\begin{array}{l}\text { Sedation, nausea, headache, } \\
\text { priapism (rare) }\end{array}$ & Postural hypotension, arrhythmias (rare) \\
\hline Mirtazapine & $\begin{array}{l}15 \mathrm{mg} \text { every hour } \\
\text { of sleep }\end{array}$ & $\begin{array}{l}45 \mathrm{mg} \text { every hour of } \\
\text { sleep }\end{array}$ & $\begin{array}{l}\text { Sedation, somnolence, dry mouth, } \\
\text { anticholinergic effects, dizziness } \\
\text { agranulocytosis (rare) }\end{array}$ & \\
\hline
\end{tabular}


Table 3 Neuropsychiatric side effects of common cardiovascular medications

\begin{tabular}{|c|c|c|c|c|c|c|c|}
\hline & Agitation/anxiety & Delirium & Depression & Hallucinations & $\begin{array}{l}\text { Mania hypomania } \\
\text { euphoria }\end{array}$ & Seizures & Sleep problems \\
\hline Amiodarone & & + & + & & & & + \\
\hline$\beta$-Blockers & & + & + & + & & + & ++ \\
\hline Captopril & & + & + & + & + & & \\
\hline Clonidine & & & & & + & & + \\
\hline Diltiazem & & + & + & + & + & & + \\
\hline Digoxin & & + & & + & + & + & + \\
\hline Doxazosin & $+(2.4 \%)$ & + & & & & & \\
\hline Disopyramide & & + & & + & & + & \\
\hline Enalapril & + & + & + & & & & \\
\hline Felodipine & & & + & & & & \\
\hline Hydralazine & & & + & & + & & \\
\hline Lidocaine & & + & & & & + & \\
\hline Lisinopril & & & + & & & & \\
\hline Mexilitene & & + & & & & + & \\
\hline Nicardipine & + (rare) & + & + & & & & \\
\hline Nifedipine & & & + & & & & + \\
\hline Prazosin & & + & + & & & & \\
\hline Procainamide & & & + & + & + & & \\
\hline Propanolol & & & + & & + & & \\
\hline Quinapril & & & + & & & & + \\
\hline Reserpine & & + & & & + & & \\
\hline Spironolactone & & + & & & & & \\
\hline Streptokinase & & & + & + & & & \\
\hline
\end{tabular}

action). ${ }^{36}$ As shown in the Cardiac Arrhythmia Suppression Trial, use of drugs with class Ia or Ic are associated with increased mortality in patients with ischaemic heart disease and therefore should be avoided in such patients. ${ }^{37}{ }^{38}$ Owing to their antiarrhythmic properties, they can slow cardiac conduction, decrease ventricular irritability, and suppress ectopic activity. In the absence of pre-existing conduction abnormalities, this action is unlikely to be clinically significant at therapeutic doses. However, second degree heart block, sick sinus syndrome, bundle branch block, a prolonged QT interval, and the concurrent administration of antiarrhythmic agents are all considered contraindications to their use.

In contrast to this antiarrhythmic effect, tricyclic antidepressants can on occasion be arrhythmogenic. This is probably caused by their prolongation of the QT interval and/ or an increase in myocardial noradrenaline resulting from their peripheral inhibition of noradrenaline reuptake. Although the most common arrhythmias are atrial or ventricular premature beats, these may give way to more malignant ventricular arrhythmias. These toxic, proarrhythmic effects are seen primarily in overdose, and at therapeutic levels they are rare and more likely in those with pre-existing ischaemic heart disease, a prolonged QT interval, electrical instability, or a recent myocardial infarction. ${ }^{39}$ At toxic levels, any type of arrhythmia may be seen. These may last for three to four days after ingestion. Tricyclic antidepressants also raise heart rate by $5-20$ beats per minute, as a result of their anticholinergic blockade. They also block $\alpha$-adrenergic receptors causing orthostatic hypotension and a reflex tachycardia in up to $20 \%$ of patients. This cardiovascular effect, particularly in the elderly, may have serious consequences such as acute coronary syndromes, cerebral hypoperfusion, and falls. $^{39} 40$ This side effect is more likely to be clinically significant in patients with chronic heart failure, impaired left ventricular function, volume depletion, or in patients who are taking antihypertensive medications. There are also several interactions between the tricyclics and cardiac medications. The tricyclics interfere with neuronal reuptake of clonidine and guanethidine and thus antagonise their antihypertensive action. They may potentiate the antihypertensive action of prazosin, and the dry mouth induced may hinder the absorption of sublingual nitrates. Taking all this into account, tricyclic antidepressants should be avoided in ischaemic heart disease in particular and other cardiovascular conditions in general.

Bupropion, a non-tricyclic antidepressant that acts on both the dopamine and noradrenaline systems, causes less hypotension than the tricyclic antidepressants; does not affect cardiac rate, conduction, or contractility; and is safely used in patients with cardiac disease. It does not exacerbate ventricular arrhythmias or conduction block in patients with these conditions. $^{41}$

SSRI antidepressants are considered relatively safer. The SSRIs have superseded tricyclic antidepressants as the first line agents for treating the cardiac patient with major depressive disorder. ${ }^{42}$ In healthy patients, the SSRIs have no adverse effects on cardiac contractility or conduction and there is no evidence of cardiotoxicity in overdose. In patients with cardiac disease, they do not appear to cause significant electrocardiographic or blood pressure changes, although they can slow heart rate. More extensive investigation is still necessary, but the data thus far suggest that the SSRIs have minimal cardiovascular effects and a large margin of safety in treating patients with even very severe heart disease. ${ }^{43}$ The SSRIs have, however, the potential to interact with a number of medications used to treat cardiac disease as they inhibit hepatic cytochrome $\mathrm{P} 450$ isoenzymes. This is particularly salient with warfarin and digoxin, although the clinical significance of these interactions is not yet clear. ${ }^{44}$

Venlafaxine, the new serotonin and noradrenaline reuptake inhibitor antidepressant, affects the reuptake of both serotonin and noradrenaline. It appears to have very few cardiovascular actions and no effect on the electrocardiogram. At higher doses, however, venlafaxine has been associated with an increase of blood pressure. ${ }^{45}$ Unlike the SSRIs, it does not inhibit P450 cytochrome isoenzymes and may therefore be useful in patients on cardiac medications.

\section{Antipsychotics}

Antipsychotic drugs are used in the treatment of schizophrenia, organic psychoses, and mood disorders with psychotic features. They are also widely used in geriatric patients for agitation, confusion, excitement, and behavioural disinhibition. All antipsychotics block dopamine receptors in the brain and in the periphery. The newer atypical agents appear to 
Table 4 Interactions of psychotropic and cardiac medications: interactions involving tricyclic antidepressants and serotonergic antidepressants

\begin{tabular}{|c|c|}
\hline Medication & Effect on cardiac agent \\
\hline $\begin{array}{l}\text { Interactions involving tricyclic antidepressants } \\
\text { Type la antiarrhythmics } \\
\text { Antihypertensives: guanethidine, clonidine, } \\
\text { reserpine } \\
\text { Sublingual nitrates } \\
\alpha \text {-Adrenergic blocking agents }\end{array}$ & $\begin{array}{l}\text { Potentiate delay in cardiac conduction; heart block } \\
\text { Antagonise antihypertensive effect; potentiate } \\
\text { orthostatic hypotension } \\
\text { Oral absorption hindered by dry mouth } \\
\text { Potentiate antihypertensive effect }\end{array}$ \\
\hline $\begin{array}{l}\text { Interactions involving serotonergic antidepressants } \\
\text { Lipophilic } \beta \text {-blockers } \\
\text { Calcium channel blockers } \\
\text { Type Ic antiarrhythmics } \\
\text { Angiotensin converting enzyme inhibitors } \\
\text { Warfarin } \\
\text { Digitoxin }\end{array}$ & $\begin{array}{l}\text { Increase blood levels due to decreased hepatic } \\
\text { degradation }\end{array}$ \\
\hline
\end{tabular}

Table 5 Interactions of psychotropic and cardiac medications: interactions involving lithium and carbamazepine

\begin{tabular}{|c|c|}
\hline Medication & Effect on psychotropic or cardiac agent \\
\hline $\begin{array}{l}\text { Interactions involving lithium } \\
\text { Diuretics that cause sodium loss } \\
\text { Calcium channel blockers } \\
\text { Angiotensin converting enzyme inhibitors } \\
\text { Methyldopa }\end{array}$ & $\begin{array}{l}\text { Increase blood lithium levels } \\
\text { Enhance lithium toxicity; bradycardia } \\
\text { Enhance lithium toxicity } \\
\text { Enhance lithium toxicity }\end{array}$ \\
\hline $\begin{array}{l}\text { Interactions involving carbamazepine } \\
\text { Calcium channel blockers } \\
\text { Antiarrhythmics }\end{array}$ & $\begin{array}{l}\text { Enhance carbamazepine toxicity } \\
\text { Potentiate delay in cardiac conduction }\end{array}$ \\
\hline
\end{tabular}

exert part of their unique action through inhibition of serotonin receptors. The antipsychotic action of neuroleptic drugs reflect blockade at dopamine and/or serotonin receptors. However, many of these agents also block cholinergic, adrenergic and histamine receptors, causing a variety of side effects.

Antipsychotic use has been shown to have significant cardiac side effects. In general, these drugs affect cardiac conduction and rhythm and produce hypotension. They have $\alpha$-adrenergic blocking and quinidine-like properties, along with anticholinergic activity. They can produce prolongation of the PR and QT intervals, ST segment depression, T wave changes, ventricular arrhythmias, and heart block. Although the quinidine-like effects of the neuroleptics are usually negligible, they can become significant in patients already taking type I antiarrhythmics, in those with hypokalaemia, or

\begin{tabular}{ll}
$\begin{array}{l}\text { Table } 6 \\
\text { the QT interval of the electrocardiogram }\end{array}$ \\
\hline Antipsychotics & Antidepressants \\
\hline Thioridazine & Amitriptyline \\
Sultopride & Maprotiline \\
$\begin{array}{l}\text { Haloperido } \\
\text { Sertindole }\end{array}$ & Doxepin \\
$\begin{array}{l}\text { Chlorpromazine } \\
\text { Pimozide }\end{array}$ & Others \\
Perphenazine & Lithium \\
Trifluoperazine & \\
\hline
\end{tabular}

with clinically significant conduction delays. ${ }^{46}$ When administering a low potency neuroleptic along with an antiarrhythmic, electrocardiography should be used to monitor for conduction delays. When these agents are used together with antihypertensive agents there is more chance of orthostatic hypotension. This is of particular concern in the elderly and in acute myocardial infarction.

The higher potency neuroleptic agents, such as haloperidol and the piperazine phenothiazines, produce fewer of these effects and are therefore preferred in the presence of significant cardiac disease (especially conduction problems) and after cardiac surgery. ${ }^{46}$ Haloperidol in particular has been frequently used with safety and efficacy in severely ill cardiac patients. Oral haloperidol does not significantly affect the electrocardiogram, and intravenous haloperidol is used in acute emergencies such as agitated deliria. Intravenous administration may cause torsades de pointes, and the QT interval should therefore be monitored during aggressive, intravenous haloperidol therapy. ${ }^{47}$

Experience with the newer, "atypical" antipsychotics in cardiac patients is much more limited but suggests a generally similar profile. Clozapine can cause tachycardia and orthostatic hypotension and has significant anticholinergic activity. There are recent reports of an infrequent association of clozapine with electrocardiographic changes, arrhythmias, myocarditis, and congestive heart failure. ${ }^{48} 49$ Olanzapine produces mild orthostatic hypotension but has little effect on the electrocardiogram. Sertindole prolongs the QT interval and may therefore pose a problem in cardiac patients. Risperidone produces hypotension and has a quinidine-like effect, prolonging the QT interval, although this may occur only in overdose. 
Box 1: Summary (how to manage patients with heart disease)

- Monitor drugs causing orthostatic hypotension, particularly in the elderly.

- Avoid monoamine oxidase inhibitors, as they interact with many medications and therefore can affect the actions of other antihypertensives in a beneficial or dangerous manner.

- Venlafaxine in higher doses, clozapine, rarely tricyclic antidepressants and antipsychotics. can increase blood pressure.

- SSRIs and benzodiazepines are relatively safe to use.

\section{Stable ischaemic heart disease}

- Avoid using drugs causing orthostatic hypotension, which may exacerbate angina.

- Avoid using drugs causing tachycardia-for example, phenothiazines, clozapine, risperidone.

- Use SSRIs, as they are considered safer than tricyclic antidepressants, which may cause tachycardia or a quinidine-like effect. Avoid trazadone and nefazadone.

Acute myocardial ischaemia/period after myocardial infarction

- Avoid all antidepressants if possible for two months after myocardial infarction.

- If required, use only SSRIs (except fluvoxamine and citalopram which may be more cardiotoxic in larger doses/over doses).

- Avoid tricyclics. Because of their class la proarrhythmic properties, they may increase subsequent mortality.

- Avoid high dose antipsychotics. They can cause orthostatic hypotension and tachycardia, besides having a direct cardiac muscle suppressant effect in patients after myocardial infarction. Avoid pimozide in patients with any cardiac abnormality.

- Clozapine should be started slowly and with caution less than a year after myocardial infarction or in cardiac disease; olanzapine may be a safer alternative in the acute period after myocardial infarction.

- Anxiolytics are often prescribed because anxiety is not only uncomfortable but its concomitant sympathetic arousal can be medically dangerous. Benzodiazepines are most commonly used for this purpose and should be prescribed on a regular, round-the-clock (rather than as needed) basis.

- In the elderly and in those with compromised liver function, the shorter acting benzodiazepines (for example, oxazepam or lorazepam) are preferred, because they are cleared primarily by the kidneys.

\section{Heart failure}

- In its acute stages avoid using those medications which cause hypotension-for example, phenothiazines, clozapine, risperidone, and tricyclic antidepressants.

- $\beta$-Blockers used for psychiatric illnesses in acute cases of heart failure should be withdrawn or their dose lowered according to patient clinical status.

- Use great caution with lithium and changes in diuretic therapy.
- In chronic stable heart failure SSRIs are safe to use. However, avoid phenothiazines, clozapine, risperidone, and tricyclic antidepressants should be avoided.

\section{Arrhythmias}

- SSRIs are the first choice antidepressants for depression in patients suffering from arrhythmias (although try to avoid citalapram and fluvaxamine).

- Tricyclic antidepressants, owing to their antiarrhyth$\mathrm{mic} /$ proarrhythmic properties, can increase mortality particularly in patients after myocardial infarction.

- Avoid phenothiazines, butyrophenones, and pimozide.

- Sulpiride and olanzapine seem to be of low risk.

\section{Lithium salts (table 5)}

Lithium is used prophylactically in treating manic-depressive patients and in the treatment of manic episodes. They are also effective in treating $60 \%-80 \%$ of patients exhibiting mania and hypomania. Although many cellular processes are altered by treatment with lithium salts, the exact mode of action is unknown. It is currently proposed that lithium acts by altering the cellular concentration of a second messenger, inositol triphosphate.

In therapeutic doses, lithium exerts minimal cardiotoxicity in the majority of patients. It can be used safely in cardiac disease if initiated at a low dose, increased gradually, and monitored carefully. Benign, reversible $\mathrm{T}$ wave changes (including inversion and flattening) are common with lithium administration and are not clinically significant. Clinically significant cardiovascular side effects of lithium are

Box 2: Management of a patient with a long QT interval and requiring antipsychotic medication

- Take a careful cardiac history, remember to ask for a family history of syncope or sudden cardiac death.

- Palpitations, presyncope or syncope, spontaneously or in response to stress, shock or exertion, should prompt a cardiac referral, even in the presence of normal electrocardiography.

- Perform a careful physical examination to exclude another cardiac or neurological disorder.

- Perform a 12 lead electrocardiogram. Bear in mind that the presence of a normal QTc does not exclude the possibility of a QT interval anomaly.

- Take blood for serum potassium, calcium, magnesium, and thyroid hormone estimation. Abnormalities of these factors are potent causes of arrhythmia, and may exacerbate other causes of QT interval prolongation. The levels should be monitored and maintained within the normal range.

- If any of the above are abnormal, or a QT interval problem is still suspected, reduce or withhold medication if appropriate and seek a specialist cardiology opinion.

- If medication is essential, avoid prescribing thioridazine, chlorpromazine, or high doses of depot medication. Consider the use of adjunctive medicines such as benzodiazepines to manage acute situational disturbances, rather than high doses of antipsychotics of any class. 
Box 3: Cardiac considerations of patients requiring psychotropic medications

- History of arrhythmias, heart failure, myocarditis, and acute coronary syndromes in the preceding three months.

- Congenital long QT interval.

- Concurrent digoxin therapy.

- Concurrent use of other medicines associated with QT interval prolongation.

- History of substance misuse or heavy alcohol consumption.

- Severe hepatic or renal impairment.

- Elderly and the malnourished patients.

- Hypokalaemia.

- Hypothyroidism.

- Routine electrocardiographic monitoring for patients receiving high doses of thioridazine.

- Availability of resuscitation when using intravenous medications.

- Mandatory training in cardiopulmonary resuscitation for hospital staff.

- Particular caution with dosage in patients who are likely to be particularly susceptible to cardiovascular effects, especially those receiving class I and II cardiac antiarrhythmic drugs, frequent ventricular ectopy.

- Avoidance of other medications that may increase the risk of cardiovascular reactions such as other antipsychotic drugs; tricyclic antidepressants; SSRIs; erythromycin; and antihistamines.

very rare; they may include sinus node dysfunction and increases in ventricular irritability. In patients with heart failure, low cardiac output and low glomerular filtration, diuretic use can increase lithium levels as hyponatraemia decreases renal clearance of lithium. Lithium may still be administered to the patient on diuretics, but lithium levels must be monitored and lithium dosage may need to be reduced as much as $25 \%$ to $50 \%$, although during acute diuresis the proper adjustment of lithium is difficult because of the massive shifts in sodium and fluid balance. The elderly also require lower lithium doses because of a decline in the glomerular filtration rate. On rare occasion, lithium may worsen arrhythmias in patients with sinus node dysfunction. $^{50}$ There are also reports of idiosyncratic toxic reactions and of bradycardia when lithium is coadministered with the calcium channel blockers verapamil and diltiazem, and of lithium toxicity precipitated by the use of angiotensin converting enzyme inhibitors. Methyldopa seems to have a number of interactions with psychotropic agents, including possible toxicity when combined with lithium.

\section{Anticonvulsants}

Antiepileptics as a group are considered reasonably safe drugs when their cardiac side effects and interaction with cardiovascular medications are considered. Cardiac effects, however, are relatively more common in the older anticonvulsive agents such as sodium valproate, carbamezepine, and phenytoin. Overdose with valproate has been shown to cause cardiac conduction problems including heart block. It can also lower the platelet count and fibrinogen levels and therefore can increase the prothrombin time. ${ }^{51}$ Carbamazepine can also induce cardiac conduction abnormalities and heart blocks. ${ }^{52}$ It is known that it has quinidine-like effects and can aggravate heart block and exacerbate chronic heart failure. ${ }^{53}$ Carbamazepine can also produce hyponatraemia, and this effect is potentiated by other factors that cause hyponatraemia, such as diuretics and heart failure. ${ }^{54}$ The metabolic degradation of carbamazepine may be inhibited by calcium channel blockers, thereby increasing the risk of carbamazepine toxicity. Carbamazepine and antiarrhythmics may have additive effects in slowing cardiac conduction (table 5). ${ }^{55}$ Phenytoin has many cardiac side effects owing to its proarrhythmic and antiarrhythmic properties. It therefore has rate limiting properties on one hand and can also trigger life threatening arrhythmias particularly in vulnerable patients with background cardiac illnesses such as ischaemic heart disease, arrhythmias, and heart failure. Gabapentin and lamotrigine, the relatively newer antiepileptic agents, have a favourable pharmacokinetic profile compared with other antiepileptic drugs. In general, they have no significant cardiac effects, few other side effects, and are better tolerated than other antiepileptic drugs. ${ }^{56-58}$

\section{NEUROPSYCHIATRIC SIDE EFFECTS OF CARDIAC MEDICATIONS (TABLE 3)}

Many cardiac medications have been shown to influence the general mode, affect, and physical status of an individual. Of these, $\beta$-blockers perhaps have the most important side effects. Although, $\beta$-blockers have been used to treat some types of anxiety disorders, they can exacerbate symptoms in patients with moderate to severe depression. ${ }^{5960}$ They also cause sleep disturbances and paradoxically can lead to agitation and occasionally delirium. ${ }^{61}$ Digoxin can also have considerable central actions and have been shown to induce agitation, hallucinations, and hypomania. ${ }^{62}{ }^{63}$ Angiotensin converting enzyme inhibitors, calcium channel antagonists, and methyldopa can induce or exacerbate symptoms of depression. Doxazosin and prazosin have also been shown to cause agitation and delirium, most probably because of their action on the central nervous system. ${ }^{64}$

\section{Authors' affiliations}

S U Shah, University Hospital Birmingham and University of Birmingham, Birmingham, UK

Z Iqbal, Department of Cardiology, Ysbyty Gwynedd, Bangor, North Wales, UK

A White, S White, University Hospital Birmingham, Birmingham, UK

\section{REFERENCES}

1 Shah SU, White A, White S, et al. Heart and mind: (1) relationship between cardiovascular and psychiatric conditions. Postgrad Med J 2004;80:683-9.

2 Lopez AD, Murray CJ. The global burden of disease, 1990-2020. Nat Med 1998;4:1241-3.

3 Black DW, Fisher R. Mortality in DSM-III-R schizophrenia. Schizophr Res 1992; 7:109-16.

4 Tsuang MT, Woolson RF. Excess mortality in schizophrenia and affective disorders; do suicides and accidental deaths solely account for this excess? Arch Gen Psychiatry 1978;35:1181-5.

5 Reference withdrawn.

6 Newman SC, Bland RC. Mortality in a cohort of patients with schizophrenia: a record linkage study. Can J Psychiatry 1991;36:239-45.

7 Davies MJ. Unexplained death in fit young people. BMJ 1992;305:538-9.

8 Kannel WB, Doyle JT, MCNamara PM, et al. Precursors of sudden coronary death. Factors related to the incidence of sudden death. Circulation 1975:51:606-13.

9 Committee on Safety of Medicines. Drug-induced prolongation of the QT interval. Current Problems in Pharmacovigilance 1996;22:2.

10 Ban TA, St Jean A. Electrocardiographic changes induced by phenothiazine drugs. Am Heart J 1965;70:575-6.

11 Huston JR, Bell GE. The effects of thioridazine hydrochloride and chlorpromazine on the electrocardiogram. JAMA 1966;198:16-20.

12 Alexander CS, Nino A. Cardiovascular complications in young patients taking psychotropic drugs. Am Heart J 1969;78:757-69.

13 Ayd FJ. Cardiovascular effects of phenothiazines. International Drug Therapy Newsletter 1970;V:1-8 
14 Lapierre YD, Lapointe L, Bordeleau JM, et al. Phenothiazine treatment and electrocardiographic abnormalities. Canadian Psychiatric Association Journal 1969; 14:517-23

15 Crane GE. Cardiac toxicity and psychotropic drugs. Diseases of the Nervous System 1970;31:534-9.

16 Raj MVJ, Benson R. Phenothiazines and the electrocardiogram. Postgrad Med J 1975;51:65-8.

17 Fowler NO, McCall D, Chou TC, et al. Electrocardiographic changes and cardiacarrhythmias in patients receiving psychotropic drugs. Am J Cardiol 1976;37:223-30.

18 Deglin SM, Deglin JM, Chung EK. Drug-induced cardiovascular diseases. Drugs 1977;14:29-40.

19 Wheatley D, ed. Stress and the heart. New York: Raven Press, 1981

20 Swett CP, Shader RI. Cardiac side-effects and sudden death in hospitalized psychiatricpatients. Diseases of the Nervous System 1977;38:69-72.

21 Warner JP, Barnes TRE, Henry J. Electrocardiographic changes in patients receiving neuroleptic medication. Acta Psychiatr Scand 1996;93:311-13.

22 Buckley NA, Whyte IM, Dawson AH. Cardiotoxicity more common in thioridazine overdose than with other neuroleptics. Clinical Toxicology 1995;33:199-204.

23 Jusic N, Lader M. Post-mortem antipsychotic drug concentrations and unexplained deaths. Br J Psychiatry 1994; 165:787-91.

24 Thomas SHL. Drugs, QT interval abnormalities and ventricular arrhythmias. Adverse Drug Reactions and Toxicology Review 1994;13:77-102.

25 Fulop G, Phillips RA, Shapiro AK, et al. EEG changes during haloperidol and pimozide treatment of Tourette's disorder. Am J Psychiatry 1987;144:673-5.

26 Committee on Safety of Medicines. Cardiac arrhythmias with pimozide (Orap). Current Problems in Pharmacovigilance 1995:21:2.

27 Guillan RA, Yang C-P, Hocker EV. Antibody phenothiazines. Multiple antibody screening of patients under high doses. Journal of the Kansas Medical Society 1977;8:221-227.

28 Meeker JE, Herrmann PW, Som CW, et al. Clozapine tissue concentrations following an apparent suicidal overdose of clozaril. J Anal Toxicol 1992;16:54-6.

29 Jensen VE, Gotzsche O. Allergic myocarditis in clozapine treatment. Ugeskr Laeger 1994;156:4151-2.

30 Lilleng P, Morild I, Hope M. Clozapine and myocarditis. Tidsskr Nor Laegeforen 1995; 115:3026-7.

31 Office of Population Censuses and Surveys. Mortality statistics, injury and poisoning England and Wales. Series DH4 No 18. London: HMSO, 1992.

32 Stoudemire A, Moran MF. Psychopharmacology in the medically ill patient. In: Schatzberg AF, Nemeroff CB, eds. Textbook of psychopharmacology. Washington, DC: American Psychiatric Press, 1998:931-59.

33 Rossetti E, Fragasso G, Xuereb RG, et al. Antiischemic effects of intravenous diazepam in patients with coronary artery disease. J Cardiovasc Pharmacol 1994;24:55-8

34 Stoudemire A, Moran MG, Fogel BS. Psychotropic drug use in the medically ill. Psychosomatics 1990;31:377-91.

35 Beliles K, Stoudemire A. Psychopharmacologic treatment of depression in the medically ill. Psychosomatics 1998;39:S2-19.

36 Glassman AH, Roose SP, Bigger JT Jr. The safety of tricyclic antidepressants in cardiac patients: risk-benefit reconsidered. JAMA 1993;269:2673-5.

37 Cardiac Arrhythmia Suppression Trial (CAST) Investigators. Preliminary report: effect of enacinide and flecainide on mortality in a randomised trial of arrhythmia suppression after myocardial infarction. N Engl J Med 1989;321:406-12.

38 Cardiac Arrhythmia Suppression Trial II Investigators. Effect of the anti arrhythmic agent moricizine on survival after myocardial infarction. N Engl J Med 1992;327:227-33

39 Glassman AH, Preud'homme XA. Review of the cardiovascular effects of heterocyclic antidepressants. J Clin Psychiatry 1993;54(suppl): 16-22.

40 Neshkes RE, Gerner R, Jarvik LF, et al. Orthostatic effect of imipramine and doxepin in depressed geriatric outpatients. J Clin Psychopharmacol 1985;5:102-6.
41 Roose SP, Dalack GW, Glassman AH, et al. Cardiovascular effects of bupropion in depressed patients with heart disease. Am J Psychiatry 1991; 148:512-16.

42 Nelson JC, Kennedy JS, Pollock BG, et al. Treatment of major depression with nortriptyline and paroxetine in patients with ischemic heart disease. Am J Psychiatry 1999; 156:1024-8.

43 Roose SP, Glassman AH, Attia E, et al. Cardiovascular effects of fluoxetine in depressed patients with heart disease. Am J Psychiatry 1998; 155:650-5.

44 Harvey AT, Preskorn SH. Cytochrome P450 enzymes: interpretation of their interactions with selective serotonin reuptake inhibitors. I. J Clin Psychopharmacol 1996;16:273-85.

45 Feighner JP. Cardiovascular safety in depressed patients: focus on venlafaxine. J Clin Psychopharmacol 1995:56:574-9.

46 Stoudemire A, Moran MG, Fogel BS. Psychotropic drug use in the medically ill: II. Psychosomatics 1991;32:34-46.

47 Hunt N, Stern TA. The association between intravenous haloperidol and torsades de pointes. Psychosomatics 1995;36:541-9.

48 Lieberman JA. Maximizing clozapine therapy: managing side-effects. J Clin Psychiatry 1998;59(suppl 3):38-43.

49 Kilian JG, Kerr K, Lawrence C, et al. Myocarditis and cardiomyopathy associated with clozapine. Lancet 1999;354:1841-5.

50 Stekler TL. Lithium- and carbamazepine-associated sinus node dysfunction: nine-year experience in a psychiatric hopsital. J Clin Psychopharmacol 1994;14:336-9.

51 Davis R, Peters DH, McTavish D. Valproate. A reappraisal of its pharmacological properties and clinical efficacy in epilepsy. Drugs 1994; 47:332-72.

52 Benassi E, Bo GP, Cociot L, et al. Carbamazepine and cardiac conduction disturbances. Ann Neurol 1999;22:280-1.

53 Levy RH, Kerr BM. Clinical pharmacokinetics of carbamazepine. J Clin Psychiatry 1988;49(suppl):58-61.

54 Van Amelsvoort T, Bakshi R, Devaux C, et al. Hyponatremia associated with carbamazepine and oxcarbazepine therapy: a review. Epilepsia 1994;35:181-8.

55 Spina E, Pisani F, Perucca E. Clinically significant pharmacokinetic drug interactions with carbamazepine. An update. Clin Pharmacokinet 1996;31:198-214.

56 McElroy SL, Keck PE. Antiepileptic drugs. In: Schwartzberg AF, Nemeroff CB, eds. The American Psychiatric Press textbook of psychopharmacology. Washington, DC: American Psychiatric Press, 1995:351-75.

57 Goa KL, Sorkin EM. Gabapentin. Drugs 1993;46:409-27.

58 Fitton A, Goa K. Lamotrigine: an update of its pharmacology and therapeutic use in epilepsy. Drugs 1995;50:691-713.

59 Gengo FM, Gabos C. Central nervous systems considerations in the use of beta-blockers, angiotension-converting enzyme inhibitors and thiazide diuretics in managing essential hypertension. Am J Cardiol 1988;116:305-10.

60 Thiessen BQ, Wallace SM, Blackburn JL. Increased prescribing of antidepressants subsequent to beta-blocker therapy. Arch Intern Med 1990;150:2286-90.

61 Houston MC, Hodge R. Beta-adrenergic blocker withdrawal syndromes in hypertension and other cardiovascular diseases. Am Heart $J$ 1988; 116:515-22.

62 Schleifer SJ, Slater WR, Macari-Hinson MM, et al. Digitalis and beta-blocking agents: effects on depression following myocardial infarction. Am Heart J 1991; 121:1397-402.

63 Eisendrath SJ, Sweeney MA. Toxic neuropsychiatric effects of digoxin at therapeutic serum concentrations. Am J Psychiatry 1987; 144:506-7.

64 Levenson JL. Cardiovascular disease. In: Stoudemire A, Fogel BS, eds. Psychiatric care of the medical patient. New York: Oxford University Press, 1993:539-63. 